\title{
TECCIENCIA
}

\section{Application of ultrasound in medicine Part ii: the ultrasonic transducer and its associated electronics.}

\author{
Aplicación del ultrasonido en la Medicina: \\ Parte II: Transductor ultrasónico y sus componentes electrónicos asociados
}

\author{
Fernando A. Soler López ${ }^{1}$, Manuel A. Mayorga Betancour ${ }^{2}$, Emeterio Cruz Salazar $^{3}$ \\ ${ }^{1}$ Escuela Colombiana de Carreras Industriales (ECCI), Bogotá, Colombia, rectoria@ecci.edu.co \\ ${ }^{2}$ Escuela Colombiana de Carreras Industriales (ECCI), Bogotá, Colombia, mmayorgab@ecci.edu.co \\ ${ }^{3}$ Escuela Colombiana de Carreras Industriales (ECCI), Bogotá, Colombia, ecruzs@ecci.edu.co
}

\begin{abstract}
This paper introduces the reader to a review and analysis of various ultrasound (us) applications in the medical field. First, the transducer is shown, along with a diagram of the basic electronics that it uses to generate and receive signals that allow the reconstruction of images, for medical purposes. Also, us practical uses in medical therapy is shown. This subject is addressed by combining the physical principles involved in the us application, with the implemented technology and the modes of operation for non-invasive studies of pathologies related to brain, heart, and eyes such as injuries, tumors and hematomas. The methodology used in this article also suggests an analysis method for the us scientific and technological research principles combined for their implementation in medical applications.
\end{abstract}

Keywords: ultrasonic transducer, piezoelectric, transmitter, receiver, converter, modes

\section{Resumen}

En este trabajo se presenta al lector una revisión y análisis de diferentes aplicaciones del ultrasonido (us) en el campo médico. Inicialmente se muestra el transductor y un esquema de su electrónica básica asociada usada para emitir y adquirir las señales que permiten la reconstrucción de las imágenes, para efectos médicos y también la aplicación del us para terapia; la temática se aborda conjugando los principios físicos asociados a la aplicación del us con la tecnología implementada y sus modos de operación, para estudios no invasivos de patologías relacionadas con el cerebro, el corazón, los ojos y lesiones tales como tumores y hematomas. La metodología implementada en este artículo sugiere también un método de análisis de los principios científicos del us e investigación tecnológica asociadas para su concreción en las aplicaciones médicas.

Palabras clave: transductor ultrasónico, piezoeléctrico, transmisor, receptor, convertidor, modos

\section{Introduction}

In the last issue of TECCIENCIA, the first section of this paper was discussed. It was called "Ultrasound Applications to Medicine Part I: Physical Principles", and it described various Ultrasound (US) applications in medicine and their importance. It emphasized the physical phenomena associated with the basic principles of US (reflection, refraction and absorption) and the physical quantities associated with these phenomena, which include technological characteristics, namely the reflection coefficient, the refractive index, the attenuation coefficient, resolving power, density, intensity, frequency and impedance. The preceding is necessary to understand the way ultrasonic equipment and all of its components (especially the transducer) operate, as well as the versatility of its medical uses. The latter will be systematically discussed in this issue, "Part II: The Ultrasonic Transducer." There are different methods to generate or produce ultrasound, some of which are:

- US generation by magnetostriction.

- Electrodynamic US generation. 
- Electrostatic US generation.

- Piezoelectric US generation.

The two first methods are not relevant, due to their small generator effect and the third is not appropriate for biological tissues. Thus, only piezoelectric generation is used in medical applications; in order to do this, it is necessary to use a particular type of piezoelectric material which is able deliver optimum collimation of its US light beam, optimum lateral image resolution and small diffraction effects [1].

Piezoelectric elements are fundamental in the construction of an Ultrasound Transducer. These are responsible for producing a voltage between its two surfaces when they become deformed, or rather they become deformed when voltage is applied between their elements. In short, these are transducers that convert electric energy into mechanical energy and vice versa [2].

Among the substances used in the construction of these devices, we find certain crystal structures which contain a piezoelectric effect, such as natural quartz, barium titanate, Rochelle salts, more evolved man-made crystals like ammonium dihydrogen phosphate (ADP) and lead zirconate titanate (PZT). This last crystal is the most popular in medical ultrasound, although quartz and other materials can be used as well. PZT is commonly used in ceramic transducers, and the crystal is reduced to $\lambda / 2$ in the frequency of the ultrasonic signal being used. This causes a resonant effect that facilitates the mechanical vibration of the device. Other materials that improve the ceramic texture are also being studied (polymers, for instance) because of the homogeneity in their composition and their easy processing conditions. This allows a cost reduction [3] [4]. It is important to acknowledge that silicon-based electrostatic transducers rival the performance of the piezoelectric ones [5]. Composite materials are favorable for "dual-mode" transducers, due to their improved and wider bandwidth, which benefits the imaging performance and maintains a high level of efficiency for the treatment [6].

On both sides of the piezoelectric element electrodes are affixed. They are deposited by electrolytic means and can be connected to the electronic oscillator in the ultrasound generation process (conversion from electric energy to mechanical energy). They can also be connected to the appropriate amplifier when ultrasound echoes are received (voltage generation).

Figure 1. Illustrates an ultrasound transducer diagram. Its core is piezoelectric crystal, which is fed by electrodes that are used to apply electric voltage flashes in order to produce the ultrasound. Another option is to take the echo-produced voltages in the reverse direction.

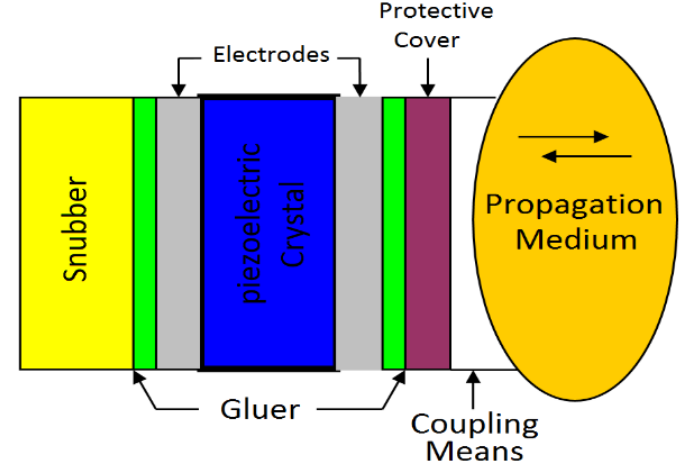

Figure 1. US Transducer

The rear electrode is affixed to the backing material, which acts as a damper to prevent excessive vibration from the generated oscillations and interference, and as the rear face of the device. In the front part, a protective layer is found, where the coupling medium is used (gel or oil) to maintain adequate acoustic impedance between the oscillator and the tissue [7].

In order to model the US transducer, some basic relations have been established for US transducers with a central hole intended for the addition of a diagnostic device [8]. In general terms, it is necessary to carry out an adaptation between the mechanical and the electric side of the transducer [9] [10]. The electromechanical system (from the electric generator to the propagation medium) is a band-pass filter [11]. Figure 2. illustrates the equivalent circuit:

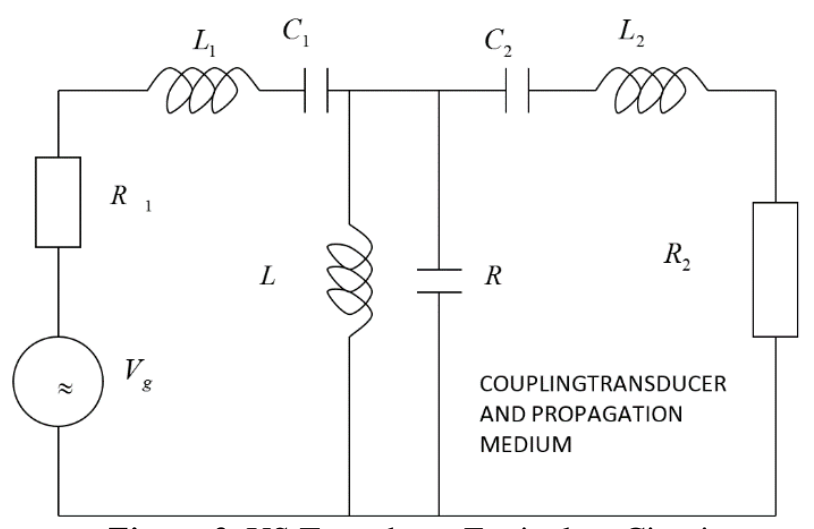

Figure 2. US Transducer Equivalent Circuit

The band-pass filter is symmetrical and works in both directions, as a sender (when the transducer converts from electric energy to mechanical energy), and as a receiver (when it converts mechanical energy to electric energy). The condenser $C_{1}$ is the electric capacity contained within the transducer, and the resonance frequency is determined by $L$ and $C . C_{2}, L_{2}$, and $R_{2}$ represent, respectively, the transducer impedance, the coupling medium, and the propagation medium. 


\section{TECCIENCIA}

\section{Applications of ultrasound to medicine}

\subsection{Approaches}

Ultrasound is used in medicine for therapy and diagnosis [12] [13] [14]. The main differences among the various devices used for this purpose are the operating frequency and the sonic intensity. Table No. 1 shows some operational ranges found in the academic literature [15] [16] [17] [18] [19] [20] [21] [22] [23]

Table 1. Medical Ultrasound Equipment

\begin{tabular}{|c|c|c|}
\hline & THERAPY & DIAGNOSIS \\
\hline FRECUENCY & $<1 \mathrm{MHz}$ & $>1 \mathrm{MHz}$ \\
\hline INTENSITY & $0.05-3 \mathrm{~W}$ & $<10 \mathrm{~mW}$ \\
\hline
\end{tabular}

In order to give a diagnosis, the doctor needs to be aware of the various physical magnitudes of the object being diagnosed. The ultrasound helps measure two physical magnitudes: distance and speed [24]. Using these magnitudes, the doctor can deduce others that will help in the diagnosis. For example, a doctor may be able to calculate blood flow using the velocity of blood circulation [25] [26] [27]

\subsection{Different measurement procedures using US}

Figure 3. illustrates the main measurement procedures using US. These are based on the application of the physical principles for this particular type of mechanical wave motion [28]. In order to choose the most adequate procedure for each application, different methodologies have been designed, such as algorithms and expert systems [29] [30] [31] [32] [33] [34] [35]

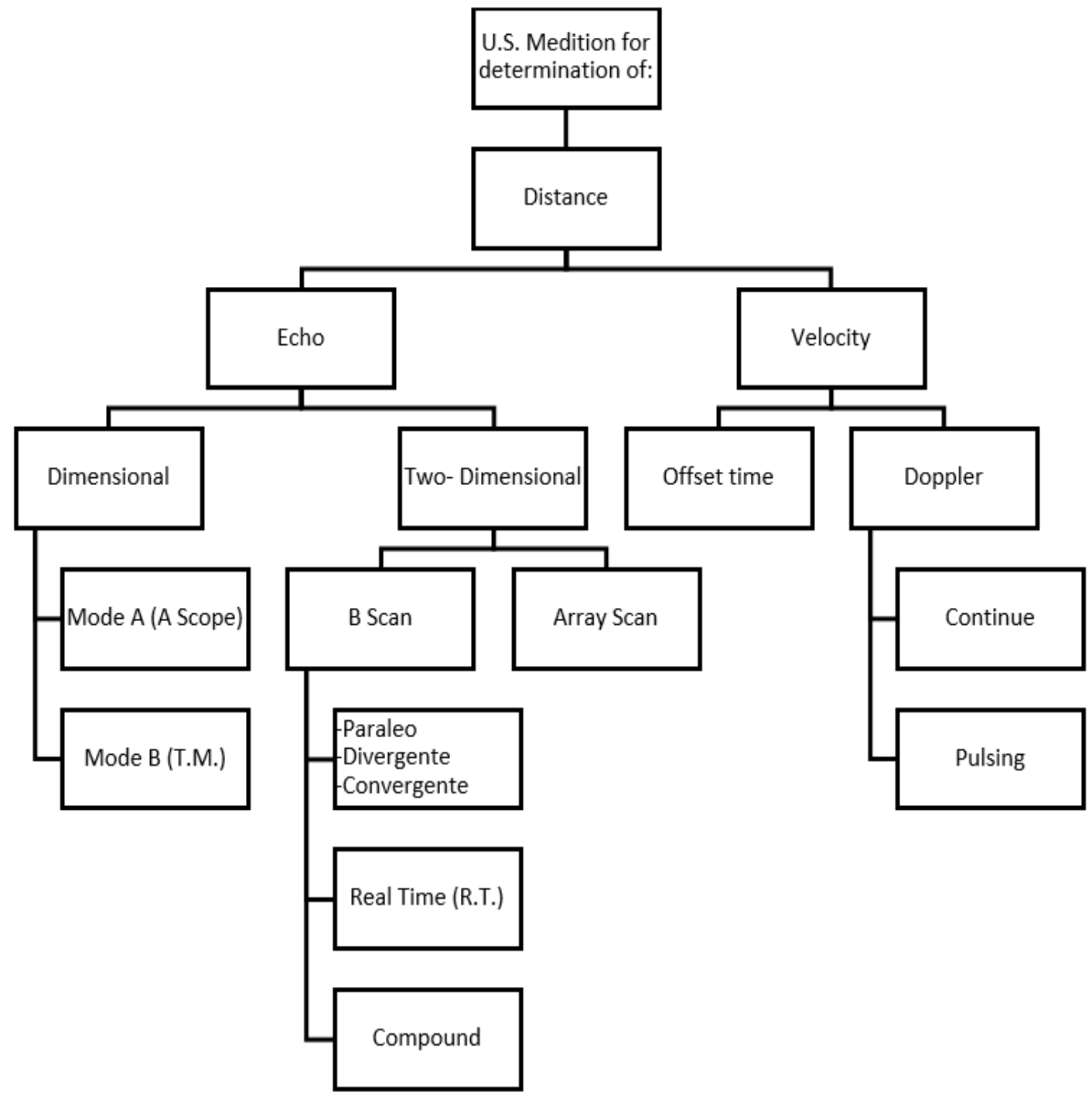
A: Amplitude
B: Brightness
T.M.: Time Motion

Figure 3. US Measurement Processes 


\section{TECCIENCIA}

\section{One-dimensional processes}

\subsection{Distance Measurement}

For distance measurement, the physical principle of echo generation (produced by step changes in the acoustic impedance of constraining structures) is used among different tissues. This results in the reflection of part of the emitted energy [36]. Limitations, such as low accuracy (which increases in cases of critical condition) and risk of exposure associated with some traditional diagnoses made through physical examination, a blood test or an ionizing radiographic test, can be overcome with the use of an ultrasound scan. This is a safe, painless, non-invasive tool, unlike what happens with respiratory track lesions [37].

As was explained, the proportion of reflected energy, $\boldsymbol{\sigma}=$ $\boldsymbol{r}^{2}$, expressed as a percentage, determines the value of the relative reflected energy in relation to water. Thus, it is possible to complete and summarize the ultrasonic variables (Part I, Table 1) in the following Table No. 2:

Table 2. Reflected Energy Proportions in Relation to Water.

\begin{tabular}{|c|c|c|}
\hline MEDIO & $\begin{array}{c}\boldsymbol{Z}=\boldsymbol{\rho c} \\
\mathbf{1 0} \times \mathbf{c m}^{\mathbf{s}} \boldsymbol{\sigma}\end{array}$ & $\begin{array}{c}\boldsymbol{\sigma}=\boldsymbol{r}^{\mathbf{2}} \mathbf{1 0 0} \% \\
\mathbf{\%}\end{array}$ \\
\hline Air & 0,00043 & 99,88 \\
\hline Water & 1,49 & 0,00 \\
\hline Muscle & 1,63 & 0,20 \\
\hline Spinal Cord & 1,65 & 0,26 \\
\hline Brain & 1,58 & 0,08 \\
\hline Fat & 1,37 & 0,17 \\
\hline Bone & 6,20 & 37,51 \\
\hline
\end{tabular}

From Table 2 three groups can be derived:

- Air

- Bones

- Water, muscles, spinal cord, brain and fat

In the latter group, the weak relationship of the tissue limits means that:

- A highly sensitive receptor is required in order to receive weak echoes

- Otherwise, it is possible that successive tissue layers are imaged as just a single sonic beam.

It can also been concluded from Table No. 2, that the US is not the ideal device to image tissues behind bones, or tissues from areas which contain gas.

\subsection{Mode A (Amplitude)}

Mode A is a one-dimensional process, where short US impulses are emitted over the observed object. These impulses generate echoes in the different constraining surfaces among tissues, which can be received by the same ultrasonic head that acts as a sender as well.

The electronically-amplified echoes are brought to the vertical entrance of an oscilloscope (part of the equipment), while keeping the time base constant. In other words, the image is achieved by impulses where the amplitude is proportional to the amount of reflected energy, and when the distance in the time axis is proportional to the distance among the constraining surfaces of the tissues. In order to achieve a stable image, this process is repeated with the same frequency.

Assuming a constant speed of sound, the error caused by the change in density among tissues of the same group is not relevant in the diagnosis [38]. The schematic representation of a measurement using Mode A, as shown in Figure 4, is implemented by the following elements:

- The pulse or flash generator, that simultaneously works as the shooter for the time base of the oscilloscope.

- The echo amplifier at the vertical entrance of the oscilloscope.

- The piezoelectric crystal, or two-way transducer.

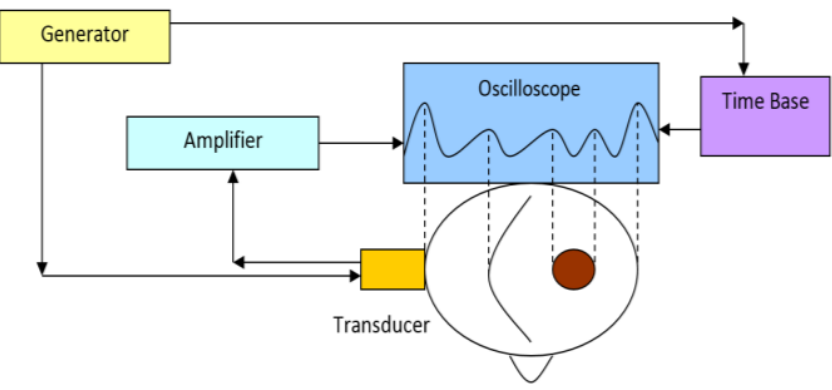

Figure 4. Mode A.

In order to compensate for the absorption of the US in biological tissues, time gain compensation is used. This means that the echoes with the lowest propagation speed are amplified to a lesser degree than those that have a higher propagation speed, in the journey of the time base [39]. This way, a clearer and more uniform image can be displayed. As an example on how Mode A can be applied, we find echoencephalography or US encephalography, and echophthalmology or US ophthalmology [40].

Echoencephalography detects brain anomalies like tumors, hematoma, injuries, displacement of the brain ventricles, etc. [41]. The test is made by placing the ultrasonic head above the right or left ear. The following image is obtained inside a healthy skull (Figure 5): 


\section{TECCIENCIA}

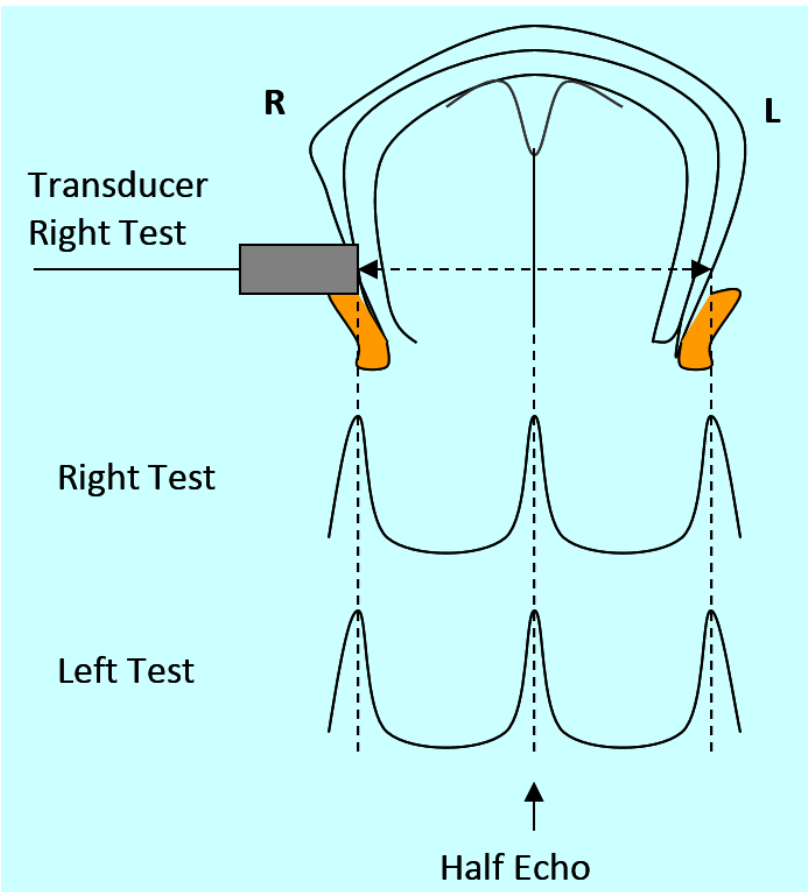

Figure 5. Echoencephalogram in a healthy skull.

Attention is to be centered on the mid-echo, which is an important element in diagnosis, since, in normal cases, it appears in the same place, regardless of whether the ultrasonic head is placed on the right or on the left.

In a case where the middle brain structures have been displaced (for example by the presence of an odd mass in a lobe that pushes them into the other lobe), a displacement is also shown in the image of the echoes, as illustrated in Figure 6:


Figure 6. Echoencephalograms in non-healthy cases.
Depending on the magnitude of the echoes and the type of displacement, the location and size of the tumors and hematomas can be diagnosed [42]. The example above is a case of distance measurement through a one-dimensional echo, Mode A.

An echoencephalogram block diagram is shown is Figure 7:

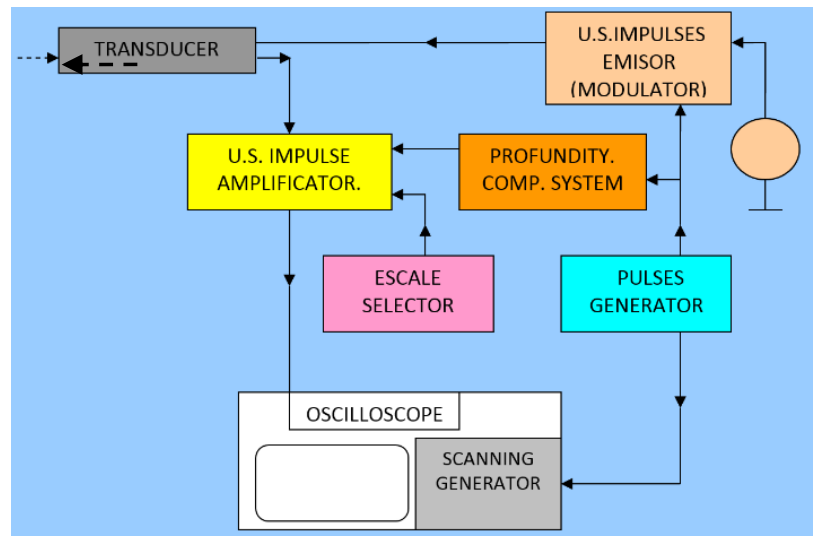

Figure 7. Echoencephalograph Block Diagram

Echoencephalograph Technical data:

Frequency

Typically $10 \mathrm{MHz}$ :

Head diameter

Average Intensity

Impulse Frequency

Amplification

Depth Compensation

Range of Measurement

$$
\begin{gathered}
1-35 \mathrm{MHz} \\
10-20 \mathrm{~mm} \\
1-10 \mathrm{~mW} / \mathrm{cm}^{2} \\
200-2000 \mathrm{~Hz} \\
100 \mathrm{~dB} \\
100 \mathrm{~dB}(\max ) . \\
1-50 \mathrm{~cm}
\end{gathered}
$$

\subsection{Mode B - Time Motion (T.M.)}

\subsubsection{Mode B}

In Mode B, the echoes are represented not as impulses but rather bright dots, and B stands for Brightness. Therefore, we can talk about a brightness mode in which the intensity of the bright dots corresponding to the echoes are represented depending on their brightness level. This has been used to evaluate steatotic liver tissues [43], intravascular tissues [44] [45] and vocal cords [46] .

With the development of the multi-transducer, or transducers with bidirectional rotation movements and lateral displacement, Mode B allowed for two dimensional imaging, as will be explained later. First, the application of Mode B in the Time Motion (TM) process will be explained [47].

Figure 8 is a brief schematic representation of Mode B, showing a hypothetical case of three lineal transducers imaging echo dots, where luminosity corresponds to echo intensity. 


\section{TECCIENCIA}

In order to achieve brightness modulation, one needs a screen with persistence that operates the amplified signal through the control grid, or through a computerized system that images the echoes as bright dots [48].



Figure 8. Mode B reproduction.

Figure 8. illustrates a multi-elemental case that is converted into TM when the US head is either transversally or laterally displaced, depending on in which direction one wishes to expand the coverage of the image.

\subsubsection{Time Motion (T.M.) o Mode M.xxx}

The imaging of surface limits is done by directing the bright dot signals to the grid of a cathode ray tube, multiplexing one element at a time and thus modulating the brightness depending on the amplitude of each echo. In the sectorial reproduction equipment, multiplexing corresponds to the rotation of a discrete angle, awaiting, step by step, the echoes of each $H_{n}$ pulse.

Thus, there is a movement of the bright dots towards the direction of the beam that corresponds to the movement of the constraining surfaces of different tissues [49]. These movements are registered by the T.R.C screen or through decoding and demodulation in flat screens or computer screens with imaging algorithms. [50] [51] The principal application of T.M mode is in real-time echocardiographs. These allow a cardiological visualization of the behavior of the valves and walls of the myocardial cavities [52] [53]

Through echocardiography it is possible to determine heart failures, especially mitral stenosis, mitral insufficiency and opening and closing valve failure. It is also possible to determine the movement of the heart's walls, the enlargement of the ventricles, and, indirectly, their volume, congenital failure, traumas, etc. [54].

In order to run the test, the ultrasonic head is slid across the patient's chest, so that the US beam reaches the part of the heart that will be analyzed. This can be done through the intercostal space.
Figure 9 is an illustration of the cross-section of the heart, in which the application of the transducer and the different structures that can be reached by various ultrasound exploration beams are shown.



Figure 9. Echocardiagraphic exploration

The echocardiographer primarily consists of a transmitterreceiver set that handles information about location by receiving ultrasonic echoes. These are converted into numeric codes by an analog-to-digital converter, and transferred to a temporary memory buffer that allows postprocessing of the image. Here, the grey levels are codified according to echo intensity, already registered in binary code, and the time gain control is taken into account based on echo depth.

In this type of examination, the patient does not require special preparation; the procedure is to apply the transducer through an adequate gel over the specific zone (in this case the intercostal space), and it works to adapt the sonic impedance, to serve as a mechanical means of transmission. Typical transducer resonance frequencies are:2,25 $\mathrm{MHz}$, 3,5 $\mathrm{MHz}, 5 \mathrm{MHz}$, and 7,5 $\mathrm{MHz}$.

When the transducer is applied, the image is displayed on the screen, and then, with small movements, the referenced physiological structures can be found. Once found, one proceeds to the adjustment of the Time Gain Control (TGC), general gain, mode, etc., in order to achieve the optimal image [55]. With practice, these operations become routine to the operator and, in a few seconds, the controls are adjusted, in order to observe different body parts that require different types of treatment and a different depth of observation [56].

The image can be documented through the various aids that are normally included in the equipment, such as calipers or registration reminders (name of the patient, sex, date, type of exam, etc.). 
To adjust the general gain in gynecological and obstetric explorations, the vesicle repletion is taken as a reference. It is necessary to inform the patient in advance of the need to drink liquids before the test. When the bladder is full of liquid, the background image is dark and free of internal echoes [57].

Another appropriate technique in echocardiography is the contrast-enhanced ultrasound, where micro-bubbles are injected, improving the echogenicity of the cavities. Analyzing the irrigated areas makes it easier to study tissue perfusion, allowing the detection of anomalies that are not visible in the classic ultrasound scan, such as different types of cancer [58] [59].

\section{Components in an ultrasonic ultrasound equipment}

\subsection{The Transducer}

The transducer is the main element of the equipment and has heretofore been described in simple terms. In practice, however, one sees that major technological development has occurred, including high-power efficient pocket-controllers [60] and portable controllers for remote locations [61] [62]. Programmable, low-cost machines are needed, as well as those for real-time clinical use, and to this end efforts in research and development are currently being carried out [63].

The element must be screened to avoid Radiofrequency (RF) radiation, because the signals emitted by the transducer are in the 1 to $10 \mathrm{MHz}$ band, where various radiocommunication services operate. Also, it is necessary to identify the reliability of the source in relation to outlet pressure [64].

Sectorial transducers are normally mechanical, with stepper motors to allow the emission and reception of the ultrasonic beams in angular, discrete, high-speed scanning. Here, the contact window must be taken into account in terms of acoustics, and the liquid that fills the ultrasound head (which contains the piezoelectric ceramic of the transducer) must be free from air bubbles, which could produce points of acoustic shadow. The sectorial transducer requires one coaxial channel that handles the temporary multiplexing, corresponding to an angular reproduction in the equipment [65].

Linear transducers use multiple elements arranged in a line, inside which spatial-temporal multiplexing occurs where each element emits and receives the echoes, according to their locations, in a parallel collection of beams. In these transducers the frontal protective screen must be handled carefully and the tightness must be watched. An additional problem in lineal transducers is the multi-coaxial cable. It can suffer from interruptions on some lines from sudden twists or rough use, which modify the continuity of the image produced in the equipment [66] [67]

\subsection{The transmitter}

The transmitter is the electronic circuit responsible for applying excitation to the transducer, which is an electrical modulated pulse. Its duration is at $100 \mathrm{~ns}$ (nanoseconds), making it vibrate. The amplitude of this tension is adjustable according to the penetrating depth and the type of tissue. It is an oscillator that is gateado by the pulses it emits, that through a power amplifier impresses the transducer. Its design is special because the amplitude typically varies from $20 \mathrm{~V}$ to $600 \mathrm{~V}$ [68].

For more complex transducers, such as linear transducers, preprocessing is required, in order to apply the excitations to the various elements.

There are some transducers that use other types of excitation, like multiple pulses and salvas to improve sensitivity, reduce parasitic oscillation and diminish pulse tension. In each element, after the transmission of a pulse, a commutation is perceived. This enables the transducer to receive the echoes and allows a correspondent pause in its process before the emission of a new pulse [69].

\subsection{The receiver}

The receiver is usually a logarithmic amplifier with gain control, because the deep echoes are received in an attenuated form. It is an amplifier with a broad spectrum, whose bandwidth is between 1 and $10 \mathrm{MHz}$. It must handle gains with a dynamic margin of 80 to $120 \mathrm{~dB}$, because these are in a range of $10^{4}$ to $10^{6}$. The system is programmed so that the gain increases at the same rate that the echo suffers attenuation due to depth [70].

In systems where no commutator from emission to reception is used, and given that the emission pulse could damage the input stage of the receiver, a limiting circuit is placed at the entrance, in order to avoid this risk [71].

It is necessary to control the gain on the amplifier. The controllable gain amplifier allows one not only to control the normal attenuation caused by depth, but also the attenuation caused by various types of internal interfaces, hence the need to program the TGC [72].

In equipment that uses linear transducers, a delay between elements is required. Hence, phased array is used [73] to improve scanning quality through analog or digital delay lines, which cause delays between lines from 0.005 to $15 \mu \mathrm{s}$ [74]. In this case, it is necessary to care for the gain pairing of the different reception channels in the arrays, in order to 
achieve coherent images. Acoustic rectifiers have also been proposed [75]. The increase in the speed of real-time acquisition of certain 3-D echocardiographers has led to a decrease in spatial resolution, creating a significant amount of noise, which has been reduced with segmentation methods [76] [77] [78] [79] [80] [81] [82]. Techniques for abdominal application with 4D ultrasound are also being explored [83]. Figure 10. shows a block diagram of an ultrasound system.

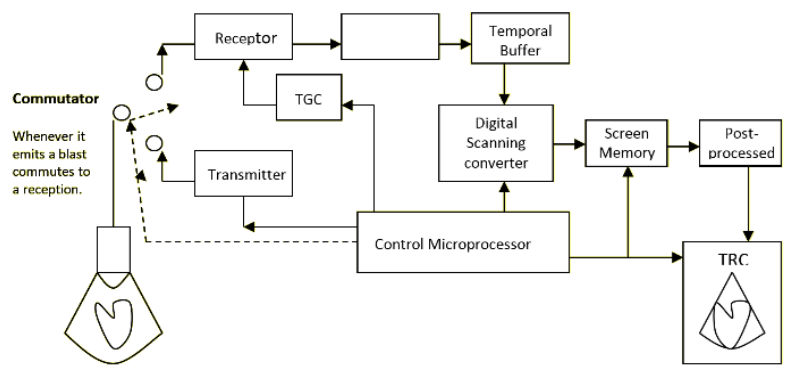

Figure 10. Block Diagram of an Ultrasound System

\subsection{Digital Scan Converter}

In order to obtain an on-screen representation from the echoes of each line (based on intensity, depth or delay, and scan geometry), the digital scan converter takes the information provided by the temporary buffer, which stores the data from the receiver that has been converted from analog to digital, and synchronizes it through the control microprocessor [84].

The first machines used analog converters which modulated the intensity in an X-Y monitor [85], permitting real-time display. Today, the need to save the image digitally in order to manipulate it and process it is fulfilled by the latest generation of machines. It is now possible to transform the information obtained from the analog-to-digital converter, namely, distance, line number, and brightness intensity, to Cartesian coordinates, directing the display memory via the control microprocessor [86] [87].

\subsection{The control microprocessor}

The control microprocessor is responsible for directing the acquisition and presentation of ultrasonic images by means of data- and writing- acquisition programs on the display memory [88].

Normally, an ultrasound machine possesses another processor to perform gating and calculations of distance, area, volume, and other measurements [89], as well as to make text presentations, record patient data, display screen auxiliary signals, indicate equipment status, etc. [90, 91].
Based on input from the writing program, the control microprocessor emits direction, control, and synchronization signals to the digital scan converter, the display memory and the display system (be it a liquid crystal display, plasma display, or TRC) [92].

\subsection{Pre- and post-processing}

The activities of image processing have a sequence. First, the location of the image lines is required, based on the runtime of the echo dots and digitally stored silences, in order for the data sequence to correspond with a line number. This is called pre-processing [93].

The post-process is the process of assigning grey levels to the binary values saved in the display memory. The alternatives used for this allocation can be as complex as desired; however, this function is normally carried out by placing a faster memory between the outlet of the memory display and the analogic-digital video converter. This quick memory contains the table that assigns the grey level, from black to white [94]. See Figure 11.

There are different forms accepted for this assignation, according to the curve selected in the design. These can achieve some effects by enhancing, softening, or adding other qualities to the image, in order to improve the visualization of the required information (a tabulation of values corresponding to each case is used, via the quick memory) [95] [96] [97]. In order to correct the speckle noise of the image, logarithmic transformations, with a Wavalet filter, are commonly used [98] [99] [100]. Finally, an exponential operation is undertaken, which may lead to a biased estimation of the signal, increasing the computational complexity. This speckle can be reduced by the use of nonhomomorphic techniques [101], or sharpening enhancement using the contourlet transform [102] [103].

If the memory placed between the outlet of the display memory and the converter is RAM memory, the user can vary the designations with the keyboard, observing the image presentation in real-time.

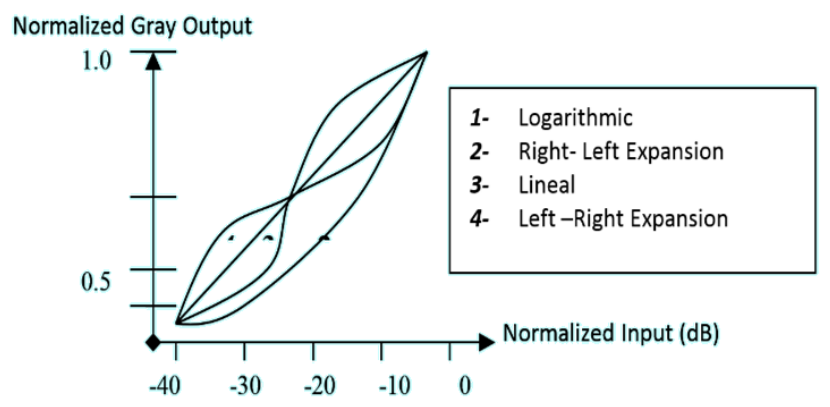

Figure 11. Various transference functions in postprocessing 


\subsection{Aids for measurement and register}

Different measurement aids are included in ultrasound machines. These are useful in quantifying many of the patient's physiological parameters, such as: distance, area, and volume calculated by ROM programs, which work with approximated formulas based on a geometrical approach. They are also based on fetal age tables (using the bi-parietal diameter of the fetus or the gating performed by the doctor) [104] [105]. New technologies, like contrast methods or elastography, improve the description of the lesions through adjustments on the image generator. [106] [107] [108] [109]

In order to be able to perform measurements, various accessories are taken into account, such as the mouse, joysticks, keyboards, printers, and remote hand-controllers [110] [111], to register the images or alternatively to save operation data for later analysis. In older versions, Polaroid cameras were used. Today, algorithms have been proposed to manage and classify (in an unsupervised fashion) the vast amount of noisy images found in the medical unit [112] [113] [114] as well as the use of fuzzy logic [115].

One interesting interface is the MIB (Medical Information Bus) application, which is used to connect to local hospital networks conforming to protocol IEEE P1073 of the IEEE Standards Board of 1984. This permits an interconnection with other devices and services.

\section{Conclusions}

The fundamental component of medical ultrasound equipment is the transducer, which uses piezoelectric material as the main source of acoustic wave generation. This material is the subject of ongoing research, in order to offer more quality, comfort and efficiency, as is the case with micromachine capacitive transducers cMTUs. They are an alternative to the conventional piezoelectric transducers, because they offer many advantages in terms of bandwidth, layer set manufacturing, efficiency and sensitivity [116].

Regarding the quality of the US images, recent research has shown the diagnostic power of generating images of unprecedented resolution, close to the quality of Magnetic Resonance Imaging (MRI), as well as the influence of nonlinear US propagation on diagnosis and therapeutic uses.

The impressive amount of medical uses of ultrasound promote the research and development of new technologies. Because it is a non-invasive method of diagnosis, it offers advantages over the $\mathrm{X}$-ray equipment, nuclear medicine and contrast methods used in different procedures.

In a research context, and especially in medicinal uses of ultrasound, it is mandatory to find the synergy between the basic sciences and their application in technological developments, in order to expand the frontier of knowledge in various fields; thus, the topic was approached from this perspective.

Throughout this paper, it was observed that ultrasound allows for more and more therapeutic diagnostic applications, from the detection of tumors and hematomas, to pathologies related to the brain, heart, etc.

Finally, it is necessary to highlight the safety and efficiency in the manipulation of ultrasound. A variety of guides and recommendations have been designed in order to improve the application of ultrasound [117] [118] [119] [120] [121] [122] [123] [124] [125] [126], as well as to improve the quality of the system [127] [128] [129] [130] and promote best practices [131].

\section{References}

[1] A. Aulet, I. Núñez, E. Moreno, J. A. Eiras and C. A. Negreira, "Design and acoustic characterization of limited diffraction ultrasonic devices.," J Acoust Soc Am, vol. 127, no. 5, pp. 27372740, \#may\# 2010.

[2] I. Chilibon, "Ultrasound transducer for medical therapy," Sensors and Actuators A: Physical, vol. 142, no. 1, pp. 124-129, \#mar\# 2008.

[3] K. H. Brosnan, G. L. Messing, D. C. Markley and R. J. J. Meyer, "Comparison of the properties of tonpilz transducers fabricated with 001 fiber-textured lead magnesium niobate-lead titanate ceramic and single crystals.," J Acoust Soc Am, vol. 126, no. 5, pp. 22572265, \#nov\# 2009.

[4] A. Abrar, D. Zhang, B. Su, T. Button, K. Kirk and S. Cochran, "13 connectivity piezoelectric ceramic-polymer composite transducers made with viscous polymer processing for high frequency ultrasound," Ultrasonics, vol. 42, no. 1-9, pp. 479-484, 2004.

[5] A. Caronti, G. Caliano, R. Carotenuto, A. Savoia, M. Pappalardo, E. Cianci and V. Foglietti, "Capacitive micromachined ultrasonic transducer (CMUT) arrays for medical imaging," Microelectronics Journal, vol. 37, no. 8, pp. 770-777, \#aug\# 2006.

[6] N. Owen, J. Chapelon, G. Bouchoux, R. Berriet, G. Fleury and C. Lafon, "Dual-mode transducers for ultrasound imaging and thermal therapy," Ultrasonics, vol. 50, no. 2, pp. 216-220, 2010.

[7] A. F. Prokop, S. Vaezy, M. L. Noble, P. J. Kaczkowski, R. W. Martin and L. A. Crum, "Polyacrylamide gel as an acoustic coupling medium for focused ultrasound therapy," Ultrasound in Medicine \& Biology, vol. 29, no. 9, pp. 1351-1358, 2003.

[8] K. Beissner, "Some basic relations for ultrasonic fields from circular transducers with a central hole.," J Acoust Soc Am, vol. 131, no. 1 , pp. 620-627, 2012.

[9] T. Johansson, J. Nilsson, L.-O. Almquist and N.-G. Holmer, "The use of ink jets in ultrasound registrations," Ultrasound in Medicine \& Biology, vol. 17, no. 5, pp. 529-539, 1991.

[10] B. Khuri-Yakub, A. Ergun, O. Oralkan and G. Yaralioglu, "2.14 Ultrasonic Transduction," in Comprehensive Microsystems, $\mathrm{H}$. Zappe, Ed., Oxford, Elsevier, 2008, pp. 517-539.

[11] J. Hatfield, N. Scales, A. Armitage, P. Hicks, Q. Chen and P. Payne, "An integrated multi-element array transducer for ultrasound imaging," Sensors and Actuators A: Physical, vol. 41, no. 1-3, pp. $167-173,1994$ 
[12] J. A. Jensen, "Medical ultrasound imaging," Progress in Biophysics and Molecular Biology, vol. 93, no. 1-3, pp. 153-165, \#jan\# 2007.

[13] T. J. Mason, "Therapeutic ultrasound an overview," Ultrasonics Sonochemistry, vol. 18, no. 4, pp. 847-852, 2011.

[14] S. Paliwal and S. Mitragotri, "Therapeutic opportunities in biological responses of ultrasound," Ultrasonics, vol. 48, no. 4, pp. 271-278, 2008.

[15] G. Clement, "Perspectives in clinical uses of high-intensity focused ultrasound," Ultrasonics, vol. 42, no. 10, pp. 1087-1093, 2004.

[16] V. S. Dogra, M. Zhang and S. Bhatt, "High-Intensity Focused Ultrasound (HIFU) Therapy Applications," Ultrasound Clinics, vol. 4, no. 3, pp. 307-321, 2009.

[17] S. K. Doshi and D. Keane, "5 - Catheter Microwave, Laser, and Ultrasound: Biophysics and Applications," in Catheter Ablation of Cardiac Arrhythmias (Second Edition), Saint Louis, W.B. Saunders, 2011, pp. 58-71.

[18] S. K. Doshi and D. Keane, "Chapter 5 - Catheter Microwave, Laser, and Ultrasound: Biophysics and Applications," in Catheter Ablation of Cardiac Arrhythmias, S. K. S. Huang, M.D. and M. Mark A. Wood, Eds., Philadelphia, W.B. Saunders, 2006, pp. 6982.

[19] G. A. Holland, O. Mironov, J.-F. Aubry, A. Hananel and J. B. Duda, "High-intensity Focused Ultrasound," Ultrasound Clinics, vol. 8, no. 2, pp. 213-226, 2013.

[20] J. W. Jenne, T. Preusser and M. Günther, "High-intensity focused ultrasound: Principles, therapy guidance, simulations and applications," Zeitschrift für Medizinische Physik, vol. 22, no. 4, pp. 311-322, 2012.

[21] J. Mamou, O. Aristizába, R. H. Silverman and J. A. Ketterling, "A perspective on high-frequency ultrasound for medical applications," Physics Procedia, vol. 3, no. 1, pp. 289-295, 2010.

[22] B. J. O'Daly, E. Morris, G. P. Gavin, J. M. O'Byrne and G. B. McGuinness, "High-power low-frequency ultrasound: A review of tissue dissection and ablation in medicine and surgery," Journal of Materials Processing Technology, vol. 200, no. 1-3, pp. 38-58, 2008.

[23] J. Serrone, H. Kocaeli, T. Douglas Mast, M. T. Burgess and M. Zuccarello, "The potential applications of high-intensity focused ultrasound (HIFU) in vascular neurosurgery," Journal of Clinical Neuroscience, vol. 19, no. 2, pp. 214-221, 2012.

[24] P. Acevedo and D. Das-Gupta, "The measurement of the spatial average temporal average intensity Isata and ultrasonic power $\mathrm{W}$ in composite ultrasonic transducers for medical application," Ultrasonics, vol. 40, no. 1-8, pp. 819-821, 2002.

[25] D. A. Christopher, P. N. Burns, J. Armstrong and F. Foster, "A highfrequency continuous-wave Doppler ultrasound system for the detection of blood flow in the microcirculation," Ultrasound in Medicine \& Biology, vol. 22, no. 9, pp. 1191-1203, 1996.

[26] D. A. Christopher, P. N. Burns, B. G. Starkoski and F. Foster, "A high-frequency pulsed-wave Doppler ultrasound system for the detection and imaging of blood flow in the microcirculation," Ultrasound in Medicine \& Biology, vol. 23, no. 7, pp. 997-1015, 1997.

[27] E. Gudmundson, A. Jakobsson, J. A. Jensen and P. Stoica, "Blood velocity estimation using ultrasound and spectral iterative adaptive approaches," Signal Processing, vol. 91, no. 5, pp. 1275-1283, \#may\# 2011.

[28] T. Whittingham, "Medical diagnostic applications and sources," Progress in Biophysics and Molecular Biology, vol. 93, no. 1-3, pp. 84-110, 2007.

[29] E. D. Übeyli, "Combining eigenvector methods and support vector machines for detecting variability of Doppler ultrasound signals,"
Computer Methods and Programs in Biomedicine, vol. 86, no. 2, pp. 181-190, 2007.

[30] E. D. Übeyli, "Doppler ultrasound signals analysis using multiclass support vector machines with error correcting output codes," Expert Systems with Applications, vol. 33, no. 3, pp. 725-733, \#oct\# 2007.

[31] E. D. Ãœbeyli, "Probabilistic neural networks employing Lyapunov exponents for analysis of Doppler ultrasound signals," Computers in Biology and Medicine, vol. 38, no. 1, pp. 82-89, \#jan\# 2008.

[32] E. D. Ãœbeyli, "Usage of eigenvector methods to improve reliable classifier for Doppler ultrasound signals," Computers in Biology and Medicine, vol. 38, no. 5, pp. 563-573, \#may\# 2008.

[33] E. D. Übeyli and Í. Güler, "Detecting variabilities of Doppler ultrasound signals by a modified mixture of experts with diverse features," Digital Signal Processing, vol. 18, no. 2, pp. 267-279, 2008.

[34] E. D. Übeyli and Í. Güler, "Improving medical diagnostic accuracy of ultrasound Doppler signals by combining neural network models," Computers in Biology and Medicine, vol. 35, no. 6, pp. 533-554, 2005.

[35] S. Bodzioch and M. R. Ogiela, "New approach to gallbladder ultrasonic images analysis and lesions recognition," Computerized Medical Imaging and Graphics, vol. 33, no. 2, pp. 154-170, 2009.

[36] H. Persson and C. Hertz, "Acoustic impedance matching of medical ultrasound transducers," Ultrasonics, vol. 23, no. 2, pp. 83-89, 1985.

[37] A. Barillari, F. De Franco and F. Colonna, "Chest Ultrasound Helps to Diagnose Pulmonary Consolidations in Pediatric Patients," Journal of Medical Ultrasound, vol. 19, no. 1, pp. 27-31, 2011.

[38] T. Klinkosz, C. J. Lewa and J. Paczkowski, "Propagation Velocity and Attenuation of a Shear Wave Pulse Measured by Ultrasound Detection in Agarose and Polyacrylamide Gels," Ultrasound in Medicine \& Biology, vol. 34, no. 2, pp. 265-275, 2008.

[39] F. A. Duck, "Nonlinear acoustics in diagnostic ultrasound," Ultrasound in Medicine \& Biology, vol. 28, no. 1, pp. 1-18, 2002.

[40] H. C. Fledelius, "Ultrasound in ophthalmology," Ultrasound in Medicine \& Biology, vol. 23, no. 3, pp. 365-375, 1997.

[41] J. J. Choi, M. Pernot, S. A. Small and E. E. Konofagou, "Noninvasive, transcranial and localized opening of the blood-brain barrier using focused ultrasound in mice," Ultrasound in Medicine \& Biology, vol. 33, no. 1, pp. 95-104, 2007.

[42] B. A. Rabkin, V. Zderic and S. Vaezy, "Hyperecho in ultrasound images of HIFU therapy: Involvement of cavitation," Ultrasound in Medicine \& Biology, vol. 31, no. 7, pp. 947-956, 2005.

[43] A. Andrade, J. S. Silva, J. Santos and P. Belo-Soares, "Classifier Approaches for Liver Steatosis using Ultrasound Images," Procedia Technology, vol. 5, no. 0, pp. 763-770, 2012.

[44] J. D. Klingensmith and D. Vince, "B-spline methods for interactive segmentation and modeling of lumen and vessel surfaces in threedimensional intravascular ultrasound," Computerized Medical Imaging and Graphics, vol. 26, no. 6, pp. 429-438, 2002.

[45] A. C. Rossi, P. J. Brands and A. P. Hoeks, "Automatic recognition of the common carotid artery in longitudinal ultrasound B-mode scans," Medical Image Analysis, vol. 12, no. 6, pp. 653-665, 2008.

[46] C.-G. Tsai, J.-H. Chen, Y.-W. Shau and T.-Y. Hsiao, "Dynamic BMode Ultrasound Imaging of Vocal Fold Vibration During Phonation," Ultrasound in Medicine \& Biology, vol. 35, no. 11, pp. 1812-1818, 2009.

[47] S. Huber, M. Wagner, M. Medl and H. Czembirek, "Real-time spatial compound imaging in breast ultrasound," Ultrasound in Medicine \& Biology, vol. 28, no. 2, pp. 155-163, 2002.

[48] N. Damodaran, S. Ramamurthy, S. Velusamy and G. Kanakaraj Manickam, "Speckle Noise Reduction in Ultrasound Biomedical B- 
Scan Images Using Discrete Topological Derivative," Ultrasound in Medicine \& Biology, vol. 38, no. 2, pp. 276-286, 2012.

[49] J. E. Kirkebo and A. Austeng, "Improved beamforming using curved sparse 2D arrays in ultrasound," Ultrasonics, vol. 46, no. 2, pp. 119-128, 2007.

[50] R. San José-Estépar, M. Martín-Fernández, P. Caballero-Martínez, C. Alberola-López and J. Ruiz-Alzola, "A theoretical framework to three-dimensional ultrasound reconstruction from irregularly sampled data," Ultrasound in Medicine \& Biology, vol. 29, no. 2 , pp. $255-269,2003$.

[51] O. V. Solberg, F. Lindseth, H. Torp, R. E. Blake and T. A. Nagelhus Hernes, "Freehand 3D Ultrasound Reconstruction Algorithms A Review," Ultrasound in Medicine \& Biology, vol. 33, no. 7, pp. 991-1009, 2007.

[52] B. Bijnens, J. D'hooge, G. Sutherland, M.-C. Herregods, J. Nuyts, P. Suetens and F. Van de Werf, "Robustness of integrated backscatter for myocardial tissue characterization," Ultrasound in Medicine \& Biology, vol. 25, no. 1, pp. 95-103, 1999.

[53] B. J. Kimura, D. J. Shaw, D. L. Agan, S. A. Amundson, A. C. Ping and A. N. DeMaria, "Value of a Cardiovascular Limited Ultrasound Examination Using a Hand-Carried Ultrasound Device on Clinical Management in an Outpatient Medical Clinic," The American Journal of Cardiology, vol. 100, no. 2, pp. 321-325, 2007.

[54] K. T. Spencer, B. J. Kimura, C. E. Korcarz, P. A. Pellikka, P. S. Rahko and R. J. Siegel, "Focused Cardiac Ultrasound: Recommendations from the American Society of Echocardiography," Journal of the American Society of Echocardiography, vol. 26, no. 6, pp. 567-581, 2013.

[55] D.-Y. Lee, Y. Yoo, T.-K. Song and J. H. Chang, "Adaptive dynamic quadrature demodulation with autoregressive spectral estimation in ultrasound imaging," Biomedical Signal Processing and Control, vol. 7, no. 4, pp. 371-378, 2012.

[56] B. Petersch, M. Hadwiger, H. Hauser and D. Hönigmann, "Real time computation and temporal coherence of opacity transfer functions for direct volume rendering of ultrasound data," Computerized Medical Imaging and Graphics, vol. 29, no. 1, pp. $53-63,2005$.

[57] L.-H. Tseng, "Ultrasound in Urogynecology: An Update on Clinical Application," Journal of Medical Ultrasound, vol. 15, no. 1, pp. 4557, 2007.

[58] A. Granata, F. Floccari, G. Daidone, V. R. Scarfia, L. Di Lullo, A. Basile, G. Battaglia and F. Fiorini, "Microbubbles: current state and future prospects," G Ital Nefrol, vol. 29, no. 57, pp. 15-24, 2012.

[59] X. Cao, J. Xue and B. Zhao, "Potential Application Value of Contrast-Enhanced Ultrasound In Neoadjuvant Chemotherapy of Breast Cancer," Ultrasound in Medicine \& Biology, vol. 38, no. 12, pp. 2065-2071, 2012.

[60] G. Lewis and W. Olbricht, "Design and characterization of a highpower ultrasound driver with ultralow-output impedance," Rev Sci Instrum, vol. 80, no. 11, pp. 114704-114704, 2009.

[61] B. P. Nelson, E. R. Melnick and J. Li, "Portable Ultrasound for Remote Environments, Part I: Feasibility of Field Deployment," The Journal of Emergency Medicine, vol. 40, no. 2, pp. 190-197, 2011.

[62] B. P. Nelson, E. R. Melnick and J. Li, "Portable Ultrasound for Remote Environments, Part II: Current Indications," The Journal of Emergency Medicine, vol. 40, no. 3, pp. 313-321, 2011.

[63] C. Basoglu, R. Managuli, G. York and Y. Kim, " Computing requirements of modern medical diagnostic ultrasound machines," Parallel Computing, vol. 24, no. 9-10, pp. 1407-1431, 1998.

[64] T. A. Bigelow and W. D. O'Brien, " «Experimental evaluation of indicators of nonlinearity for use in ultrasound transducer characterizations,»," Ultrasound in Medicine \& Biology, vol. 28 , no. 11-12, pp. 1509-1520, 2002.
[65] L. Wu and Y. C. Chen, "PSPICE approach for designing the ultrasonic piezoelectric transducer for medical diagnostic applications," » Sensors and Actuators A: Physical, vol. 75, no. 2, pp. 186-198, 199

[66] M. Martins, V. Correia, J. Cabral, S. Lanceros M. and J. Rocha, "Optimization of piezoelectric ultrasound emitter transducers for underwater communications," Sensors and Actuators A: Physical, vol. 184, no. 0, pp. 141-148, 2012

[67] Z. Yang, T. A. Tuthill, D. L. Raunig, M. D. Fox and M. Analoui, "Pixel Compounding: Resolution-Enhanced Ultrasound Imaging for Quantitative Analysis," Ultrasound in Medicine \& Biology, vol. 33, no. 8, pp. 1309-1319, 2007.

[68] B. Zeqiri, G. Zauhar, M. Hodnett and J. Barrie, " Progress in developing a thermal method for measuring the output power of medical ultrasound transducers that exploits the pyroelectric effect," Ultrasonics, vol. 51, no. 4, pp. 420-424, 2011.

[69] D. Zhao and H.-K. Cha, "A 30-V transmitter front-end IC for ultrasound medical imaging applications," Microelectronics Journal, vol. 44, no. 3, pp. 185-189, 2013.

[70] B. Raeymaekers, C. Pantea and D. N. Sinha, "Creating a collimated ultrasound beam in highly attenuating fluids," Ultrasonics, vol. 52, no. 4, pp. 564-570, 2012.

[71] S. H. Contreras O., T. Chiu and M. D. Fox, "Ultrasound image enhancement: A review," Biomedical Signal Processing and Control, vol. 7, no. 5, pp. 419-428, 2012

[72] A. Agarwal, Y. M. Yoo, F. K. Schneider and Y. Kim, "Adaptive field-of-view imaging for efficient receive beamforming in medical ultrasound imaging systems," Ultrasonics, vol. 48, no. 5, pp. 384393, 2008.

[73] P. C. Eccardt and K. Niederer, "Micromachined ultrasound transducers with improved coupling factors from a CMOS compatible process," Ultrasonics, vol. 38 , no. 1-8, pp. 774-780, 2000

[74] J. Johnson, Ã.-m. Oralkan, U. Demirci, S. Ergun, M. Karaman and P. Khuri-Yakub, "Medical imaging using capacitive micromachined ultrasonic transducer arrays," Ultrasonics, vol. 40, no. 1â€"8, pp. 471-476, \#may\# 2002.

[75] B. Liang, X. S. Guo, J. Tu, D. Zhang and J. C. Cheng, "An acoustic rectifier.," Nat Mater, vol. 9, no. 12, pp. 989-992, 2010.

[76] E. D. Angelini, S. Homma, G. Pearson, J. W. Holmes and A. F. Laine, "Segmentation of real-time three-dimensional ultrasound for quantification of ventricular function: A clinical study on right and left ventricles," Ultrasound in Medicine \& Biology, vol. 31, no. 9, pp. 1143-1158, 2005.

[77] N. Betrouni, R. Lopes, N. Makni, A. Dewalle, M. Vermandel and J. Rousseau, "Volume quantification by fuzzy logic modelling in freehand ultrasound imaging," Ultrasonics, vol. 49, no. 8, pp. 646$652,2009$.

[78] B. Liu, H. Cheng, J. Huang, J. Tian, X. Tang and J. Liu, "Probability density difference-based active contour for ultrasound image segmentation," Pattern Recognition, vol. 43, no. 6, pp. 2028-2042, 2010

[79] F. Molinari, G. Zeng and J. S. Suri, "A state of the art review on intima-media thickness (IMT) measurement and wall segmentation techniques for carotid ultrasound," Computer Methods and Programs in Biomedicine, vol. 100, no. 3, pp. 201-221, 2010.

[80] N. Betrouni, M. Vermandel, D. Pasquier, S. Maouche and J. Rousseau, "Segmentation of abdominal ultrasound images of the prostate using a priori information and an adapted noise filter," Computerized Medical Imaging and Graphics, vol. 29, no. 1, pp. 43-51, 2005.

[81] S. Olabarriaga and A. Smeulders, "Interaction in the segmentation of medical images: A survey," Medical Image Analysis, vol. 5, no. 2, pp. 127-142, 2001 
[82] J. Yu and J. Tan, "Object density-based image segmentation and its applications in biomedical image analysis," Computer Methods and Programs in Biomedicine, vol. 96, no. 3, pp. 193-204, 2009.

[83] S. H. Kim and B. I. Choi, "Three-dimensional and Fourdimensional Ultrasound: Techniques and Abdominal Applications," Journal of Medical Ultrasound, vol. 15, no. 4, pp. 228-242, 2007.

[84] M. Malinen, S. R. Duncan, T. Huttunen and J. P. Kaipio, "Feedforward and feedback control of ultrasound surgery," Applied Numerical Mathematics, vol. 56, no. 1, pp. 55-79, 2006.

[85] O. V. Solberg, F. Lindseth, L. E. Bo, S. Muller, J. B. L. Bakeng, G. A. Tangen and T. A. N. Hernes, "3D ultrasound reconstruction algorithms from analog and digital data," Ultrasonics, vol. 51, no. 4, pp. 405-419, 2011.

[86] A. Goldstein and R. L. Powis, "Medical ultrasonic diagnostics," in Ultrasonic Instruments and Devices I Reference for Modem Instrumentation, Techniques, and Technology, vol. Volume 23, A. D. P. R.N. Thurston and E. P. Papadakis, Eds., Academic Press, 1999, pp. 43--IV.

[87] C. Leung, K. Hashtrudi-Zaad, P. Foroughi and P. Abolmaesumi, "A Real-Time Intrasubject Elastic Registration Algorithm for Dynamic 2-D Ultrasound Images," Ultrasound in Medicine \& Biology, vol. 35, no. 7, pp. 1159-1176, 2009.

[88] A. Gee, R. Prager, G. Treece and L. Berman, "Engineering a freehand 3D ultrasound system," Pattern Recognition Letters, vol. 24, no. 4-5, pp. 757-777, 2003.

[89] B. Zeqiri, "Metrology for ultrasonic applications," Progress in Biophysics and Molecular Biology, vol. 93, no. 1-3, pp. 138-152, 2007.

[90] D. Ni, Y. P. Chui, Y. Qu, X. Yang, J. Qin, T.-T. Wong, S. S. Ho and P. A. Heng, "Reconstruction of volumetric ultrasound panorama based on improved 3D SIFT," Computerized Medical Imaging and Graphics, vol. 33, no. 7, pp. 559-566, 2009.

[91] J. M. Rubin, T. A. Tuthill and J. Fowlkes, "Volume flow measurement using doppler and grey-scale decorrelation," Ultrasound in Medicine \& Biology, vol. 27, no. 1, pp. 101-109, 2001.

[92] R. Bruno, R. Bruno and N. Jean-Marie, "An interactive tool to visualize three-dimensional ultrasound data," Ultrasound in Medicine \& Biology, vol. 26, no. 1, pp. 133-142, 2000.

[93] P. G. Nes, "Fast multi-scale edge-detection in medical ultrasound signals," Signal Processing, vol. 92, no. 10, pp. 2394-2408, 2012.

[94] J. Eisenbrey, J. Dave, V. Halldorsdottir, D. Merton, P. Machado, J. Liu, C. Miller, J. Gonzalez, S. Park, S. Dianis, C. Chalek, K. Thomenius, D. Brown, V. Navarro and F. Forsberg, "Simultaneous grayscale and subharmonic ultrasound imaging on a modified commercial scanner," Ultrasonics, vol. 51, no. 8, pp. 890-897, 2011.

[95] P. L. van Neer, H. J. Vos and N. de Jong, "Reflector-based phase calibration of ultrasound transducers," Ultrasonics, vol. 51, no. 1, pp. 1-6, 2011.

[96] S. H. Okazawa, R. Ebrahimi, J. Chuang, R. N. Rohling and S. E. Salcudean, "Methods for segmenting curved needles in ultrasound images," Medical Image Analysis, vol. 10, no. 3, pp. 330-342, 2006.

[97] R. W. Prager, A. H. Gee, G. M. Treece, C. J. Cash and L. H. Berman, "Sensorless freehand 3-D ultrasound using regression of the echo intensity," Ultrasound in Medicine \& Biology, vol. 29, no. 3, pp. 437-446, 2003.

[98] G. Andria, F. Attivissimo, G. Cavone, N. Giaquinto and A. Lanzolla, "Linear filtering of 2-D wavelet coefficients for denoising ultrasound medical images," Measurement, vol. 45, no. 7, pp. 1792 $1800,2012$.
[99] L. Kaur, S. Gupta, R. Chauhan and S. Saxena, "Medical ultrasound image compression using joint optimization of thresholding quantization and best-basis selection of wavelet packets," Digital Signal Processing, vol. 17, no. 1, pp. 189-198, 2007.

[100] A. Khare, M. Khare, Y. Jeong, H. Kim and M. Jeon, "Despeckling of medical ultrasound images using Daubechies complex wavelet transform," Signal Processing, vol. 90, no. 2, pp. 428-439, 2010.

[101] S. Gupta, R. C. Chauhan and S. C. Saxena, "Robust nonhomomorphic approach for speckle reduction in medical ultrasound images.," Med Biol Eng Comput, vol. 43, no. 2, pp. 189-195, 2005.

[102] S. Anand, R. Shantha Selva Kumari, T. Thivya and S. Jeeva, "Sharpening enhancement of ultrasound images using contourlet transform," Optik - International Journal for Light and Electron Optics, vol. 124, no. 21, pp. 4789-4792, 2013.

[103] R.-F. Chang, W.-J. Wu, W. K. Moon, W.-M. Chen, W. Lee and D.R. Chen, "Segmentation of breast tumor in three-dimensional ultrasound images using three-dimensional discrete active contour model," Ultrasound in Medicine \& Biology, vol. 29, no. 11, pp. 1571-1581, 2003.

[104] T. Johansson, J. Nilsson, L. Almquist and N. Holmer, "The use of ink jets in ultrasound registrations," Ultrasound in Medicine \& Biology, vol. 17, no. 5, pp. 529-539, 1991.

[105] A. Karamalis, W. Wein, T. Klein and N. Navab, "Ultrasound confidence maps using random walks," Medical Image Analysis, vol. 16, no. 6, pp. 1101-1112, 2012.

[106] R. T. O'Brien and S. P. Holmes, "Recent Advances in Ultrasound Technology," Clinical Techniques in Small Animal Practice, vol. 22, no. 3, pp. 93-103, 2007.

[107] M. O. Culjat, D. Goldenberg, P. Tewari and R. S. Singh, "A Review of Tissue Substitutes for Ultrasound Imaging," Ultrasound in Medicine \& Biology, vol. 36, no. 6, pp. 861-873, 2010.

[108] J. L. Gennisson, T. Deffieux, M. Fink and M. Tanter, "Ultrasound elastography: Principles and techniques," Diagnostic and Interventional Imaging, vol. 94, no. 5, pp. 487-495, 2013.

[109] M. Krishnakumar, "Ultrasound Elastography," Apollo Medicine, vol. 7, no. 3, pp. 224-226, 2010.

[110] F. Najafi and N. Sepehri, "A robotic wrist for remote ultrasound imaging," Mechanism and Machine Theory, vol. 46, no. 8, pp. 1153-1170, 2011.

[111] F. Najafi and N. Sepehri, "A novel hand-controller for remote ultrasound imaging," Mechatronics, vol. 18, no. 10, pp. 578-590, 2008.

[112] S. V. Aschkenasy, C. Jansen, R. Osterwalder, A. Linka, M. Unser, S. Marsch and P. Hunziker, "Unsupervised image classification of medical ultrasound data by multiresolution elastic registration," Ultrasound in Medicine \& Biology, vol. 32, no. 7, pp. 1047-1054, 2006.

[113] H. Cheng, J. Shan, W. Ju, Y. Guo and L. Zhang, "Automated breast cancer detection and classification using ultrasound images: A survey," Pattern Recognition, vol. 43, no. 1, pp. 299-317, 2010.

[114] J. L. Mateo and A. Fernández C., "Finding out general tendencies in speckle noise reduction in ultrasound images," Expert Systems with Applications, vol. 36, no. 4, pp. 7786-7797, 2009.

[115] A. M. Badawi, A. S. Derbala and A.-B. M. Youssef, "Fuzzy logic algorithm for quantitative tissue characterization of diffuse liver diseases from ultrasound images," International Journal of Medical Informatics, vol. 55, no. 2, pp. 135-147, 1999.

[116] M. S. Salim, M. Abd Malek, R. Heng, K. Juni and N. Sabri, "Capacitive Micromachined Ultrasonic Transducers: Technology and Application," Journal of Medical Ultrasound, vol. 20, no. 1, pp. 8-31, 2012.

[117] I. Butterworth, J. Barrie, B. Zeqiri, G. Zauhar and B. Parisot, "Exploiting Thermochromic Materials for the Rapid Quality 


\section{TECCIENCIA}

Assurance of Physiotherapy Ultrasound Treatment Heads," Ultrasound in Medicine \& Biology, vol. 38, no. 5, pp. 767-776, 2012.

[118] Ä. Karagoz and M. Kemal Kartal, " Improving image quality of diagnostic ultrasound by using the safe use time model with the dynamic safety factor and the effect of the exposure time on the image quality," Ultrasonics, vol. 52, no. 1, pp. 93-102, 2012.

[119] O. Sipilä, V. Mannila and E. Vartiainen, "Quality assurance in diagnostic ultrasound," European Journal of Radiology, vol. 80, no. 2, pp. 519-525, 2011.

[120] J. M. Thijssen, G. Weijers and C. L. de Korte, "Objective Performance Testing and Quality Assurance of Medical Ultrasound Equipment," Ultrasound in Medicine \& Biology, vol. 33, no. 3, pp. 460-471, 2007.

[121] M. Claudon, C. Dietrich, B. Choi, D. Cosgrove, M. Kudo, C. Nolsa, F. Piscaglia, S. Wilson, R. Barr, M. Chammas, N. Chaubal, M. Chen, D. Clevert, J. Correas, H. Ding, F. Forsberg, J. Fowlkes, R. Gibson, B. Goldberg, N. Lassau and E. Leen, "Guidelines and Good Clinical Practice recommendations for contrast Enchanced Ultrasound (CEUS) in the liver- Update 2012," Ultrasound in Medicine \&Biology, vol. 39, no. 2, pp. 187-210, 2013.

[122] M. Peolsson, V. T. S. Löfstedt, H. Stenlund, A. Arndt and J. Trygg, "Modelling human musculoskeletal functional movements using ultrasound imaging," BMC Med Imaging, vol. 10, pp. 9-9, 2010.

[123] T. Löfstedt, O. Ahnlund, M. Peolsson and J. Trygg, " Dynamic ultrasound imaging--a multivariate approach for the analysis and comparison of time-dependent musculoskeletal movements.," BMC Med Imaging, vol. 12, pp. 29-29, 2012.

[124] W. Kreider, L. A. Crum, M. R. Bailey and O. A. Sapozhnikov, "A reduced-order, single-bubble cavitation model with applications to therapeutic ultrasound.," J Acoust Soc Am, vol. 130, no. 5, pp. 35113530, 2011.

[125] F. Feng, A. Mal, M. Kabo, J. C. Wang and Y. Bar-Cohen, " The mechanical and thermal effects of focused ultrasound in a model biological material," J Acoust Soc Am, vol. 117, vol. 117, no. 4, pp. 2347-2355, 2005.

[126] J. Aarnio, G. T. Clement and K. Hynynen, " A new ultrasound method for determining the acoustic phase shifts caused by the skull bone," Ultrasound in Medicine \& Biology, vol. 31, no. 6, pp. 771$780,2005$.

[127] R. S. Adler, ",Future and new developments in musculoskeletal ultrasound," Radiologic Clinics of North America, vol. 37, no. 4, pp. 623-631, 1999.

[128] M. Afadzi, C. Davies, Y. H. Hansen, T. Johansen, Ã. K. Standal, R. Hansen, S.-E. Mösöy, E. A. Nilssen and B. Angelsen, "Effect of Ultrasound Parameters on the Release of Liposomal Calcein," Ultrasound in Medicine \& Biology, vol. 38, no. 3, pp. 476-486, 2012.

[129] L. A. Aguilar, D. A. Steinman and R. S. Cobbold, "On the Synthesis of Sample Volumes for Real-Time Spectral Doppler Ultrasound Simulation," Ultrasound in Medicine \& Biology, vol. 36, no. 12, pp. 2107-2116, 2010

[130] F. Ahmadi, I. V. McLoughlin and Chauhan y G. ter Haar, "Bioeffects and safety of low-intensity, low-frequency ultrasonic exposure," Progress in Biophysics and Molecular Biology, vol. 108, no. 3, pp. 119-138, 2012.

[131] O. Al-Bataineh, J. Jenne and P. Huber, " Clinical and future applications of high intensity focused ultrasound in cancer," Cancer Treatment Reviews, vol. 38, no. 5, pp. 346-353, 2012. 